\title{
Empirical analysis of financial contributions of tourism to the gross domestic product of nigeria.
}

\author{
Asuquo, akabom-ita ${ }^{1}$, Oti, peter a ${ }^{2}$. Etim, Effiom Asuquo ${ }^{3}$ \\ ${ }^{I}$ PH.D. Department Of Accounting Faculty Of Management Sciences University Of Calabar, Calabar-Nigeria \\ ${ }^{2}$ PH.D. Department Of Accounting Faculty Of Management Sciences University Of Calabar, Calabar-Nigeria \\ ${ }^{3}$ Department Of Accounting Faculty Of Management Sciences University Of Calabar, Calabar-Nigeria
}

\begin{abstract}
This study evaluated the financial contributions of tourism to the gross domestic product of Nigeria from 2000-2015. To achieve the study objectives, ex-post facto research design was adopted and secondary data were collected. Data collected were analyzed using ordinary least square multiple regression technique. This was aimed at determining the cause-effect relationship between financial contributions of Tourism Sector to gross domestic product of Nigeria within the period under review. Results obtained from the analysis showed that there is a significant relationship between financial contributions of Tourism Sector to gross domestic product of Nigeria. A further analysis on contributions of other related sectors such as Health Sector, Transportation Sector, etc. yielded a non-significant relationship. Arising from the above results and conclusion, it was recommended amongst others that, in order to improve on the yield of the value of gross domestic product of Nigeria, government should develop Tourism Sector and other related sectors mentioned above. The major contribution of the work is therefore the discovery made concerning the course effect relationship between financial contributions of other related sectors to the growth of gross domestic product which normally should be positive, but was discovered to be negative based on empirical result of this work. Also the growth in tourism which normally should have had a significant relationship with growth in gross domestic product was discovered to be non-significant. It is thereforesuggested that the tourism sector be accorded more attention in view of the volatility associated with revenue from petroleum products.
\end{abstract}

Keywords: Tourism growth, Gross domestic product, Hospitality industries, Tourist, Tourist destination, Tourism expenditure

\section{Introduction}

Our natural environment provides the springboard for tourism and tourism itself revolves around the natural environment. "The creation of a beautiful environment for relaxation connote that God is the originator of tourism" (Esu and Eze, 2004). It then follows that what every tourist goes to seek for in any part of the world directly or indirectly is a thing created or instituted by God; it could be a wonderful and colourful festival, carnival, spring, terrific water fall, forest, beach, animal etc.

According to World Tourism Organization (1996) "tourism is viewed as the aggregate of all phenomenon and interaction that spring from movement and temporarily stay of personsconsidered as tourists, as long as the stay does not lead to permanent residence and not for purpose of generating revenue". Man is a creative being, his ability to provide the fellow man with those materials that are indispensable to tourism add more meaning to tourism. Fifer (2008) views it as a step by step process of getting tourist attention and the totality of all enabling service provided to them during their temporarily period of visit in such a manner that they will be satisfied.

Arising from the realization that tourism sector is quite relevant to the national economy because of its contributions in term of generation of income, boosting of employment, the Nigeria government considers the tourism sector as a promising sector with numerous benefit to the entire economy.Tourism is about providing services for tourists; the service may vary according to the specific needs of the tourist based on human adventure and leisure inclination of an individual. The tourism sector is a service oriented sector which is very sensitive with robust background and forward linkage with other branches of the economy, thus, generating opportunity for employment and enhancing revenue earning capacity. It is a known fact that in Nigeria tourism has the potential to generate significant foreign exchange as noted by Okey \& Ovat (2003), thus the need for economic diversification is overwhelming and tourism is seen as a capable tool to revitalize the economy of any destination as noted by Esu \& Eze (2004) and widely accepted as one of the booming industries in the world (Lanze\& Piguaru 1999).Uduma-Olugu \& Onuk-Wube (2012) had stated that tourism is viewed by policy makers in Nigeria as alternative revenue earner. Ajoa (2012) posited that "for Nigeria to enjoy the expected benefit associated with tourism, tourism sector must be brought to the limelight of the national economy.

To arrive at the financial value created/added to the economy by tourism, the value added approach of measuring gross domestic product should be employed, this is of utmost importance because the 
increase/decrease of tourism share in contribution to the growth rate in gross domestic product may be as a result of stagnation of other sectors and vice versa. Tourism sector is an interrelated service industry whose stakeholders have to be satisfied. Policy makers in Nigeria have held several conferences geared toward improving the level of stakeholders/tourists satisfaction in different ways. Similar to other sectors, satisfaction results from several variables, mostly physiological outcome derived from the tourism experiences.

In order to create utility, tourism makes use of raw material from other sectors of the economy and converts them to tourists' goods and services for tourists at the tourists' destination. Hence it is this value created by the tourism industries that is regarded as its contribution to the gross domestic product, thus to measure tourism contribution and its magnitude, the total expenditure by the tourist can be seen to be a natural option since tourism is primarily a consumption activity.Although Tourism has been identified as an effective tool to revitalize the economy of Nigeria, this sector has not been given due attention because of the believe that its relevance in terms of financial contribution to the economy is not significant. Beside, tourism unlike crude oil is an everlasting product which could have positive influence on employment, transportation and health sectors of the economy.This sector from all indications should present ample opportunity to a developing nation like Nigeria with great opportunity and avenue for economic diversification; it therefore became necessary to examine its financial contribution to the GDP. Thus, the problem of the study is concerned with the assessment of the extent and magnitude of financial contribution by the tourism sector to the gross domestic product of Nigeria from $2000-2015$

\section{Theoretical framework}

The following theories could be used to explain the various variables that underpinned the tourism activities in the World and Nigeria in particular:

1. Theory of Public Expenditure Growth (R. A. Musgrave 1954):

2. Consumer Demand Theory (Miles Edgeworth, 1817)

3. Social Exchange Theory (Homan G., 1974).

\subsubsection{Musgrave theory of public expenditure growth (1954):}

Musgrave in his own theory found changes in the relationship between need for public recreational services in three ranges. The primary or foundational range is the level of low per capita income, which is mostly found in developing countries, where the need for public recreational facilities tends to be generally low. This stem from the fact that nearly all income is used to satisfy primary needs. Secondary level is when per capita income starts to rise above the primary level, here the need for recreational services supplied by public sector such as health, education, transport, hospitality services starts rising, forcing appropriate government agency to increase their budgeted expenditure on them. The final range is the range of high per capita income which is found in developed economies, where the rate of public sector growth tends to grow rapidly as the more basic wants are satisfied. In regard to tourism, the demand for hospitality services tends to grow proportionately with individual income, the higher the income of the tourist, the higher the demand for tourism products, which influence positively the provision of tourism related services such as health, transport, and social amenities by the government.

\subsubsection{Consumer demand theory (Miles Edgeworth, 1871)}

Since tourism is mostly a consumption activity and the products/services are solely made for the tourist, then it will be appropriate to explain the behaviour of the tourist toward their destination with the help of the law of demand. Edgeworth (1871) pointed out the following as broad categories of determinants that could be used to explain variation in the demand of a commodity.

a. Products/service price: Among price factor, there are two relevant components considered when weighing travel options. Transport costs is the first; the tourist considers the cost of travelling from his/her home country to his preferred place of visit before embarking on such visit. The transport cost to be incurred influence the tourist action positively or negatively.

In other words, transportation also includes economic cost such as the opportunity cost associated with long and uncomfortable journey,more so transportation cost for given destination can be diverse. Secondly, the in-country cost which represents the cost incurred for residing in a destination country for the short term. These might include accommodation, and other necessity and these expenses of tourist may vary significantly, among chosen destination, thus influencing the tourist positively or negatively.

b. Income variable: Since the tourist is limited by his/her disposable income, he is compelled to choose one destination over another based on his income level.

c. Socio-political variables: There are many qualitative factors influencing demand for tourism. The availability and quality of tourist attraction site in a given country might qualify as one possible act that influences the readiness for tourist to travel to a particular country. 
Protected natural resources, cultural land mark, ancestral ties, festivals are some of the attractive sites that attract a tourist to one country rather than another. However, there are some qualitative resources and political factorssuch as climatic condition that also influences the tourist choices. Political variable as a factor can influence the preference of one destination over the other. Countries with concentration of power at the centre can be expected to exhibit greater political instability and therefore would be less attractive as tourist destination.

Furthermore, socio-political variable is a very significant factor that influence tourist preference because tourist will be more likely to visit a nation with greater freedom than a nation with less freedom. A country that ispolitically unstable and crisis ridden will not be an attractive destination for tourists. For instance, the present insecurity in most of the Northern States of Nigeria serves as a great hindrance to tourism growth in the Northern region because tourists will be unwilling to visit any crises area.

\subsubsection{Social exchange theory (Homan G. 1974)}

This theory states that individuals have freedom of choice and always faced with practical situations in which they must choose among alternative competitive actions. Any action provides some gains and entail some costs associated with it. Reward can arise in forms of money, goods, services, prestige or status etc. The theory posits that individuals are rational, that is they try to maximize reward and minimize costs. Consequently, they will choose whatever actions produce the best outcome.

In relation to tourism, a tourist will consider the costs of visiting a particular destination which may include hotel charges, transport, health/safety expenses, feeding expenses etc and the perceived rewards/benefit from that destination. If the perceived reward outweigh the cost, the tourist will embark on the journey. Moreover, in term of choosing a particular destination over the other, a tourist judges the attractiveness of a relationship by comparing the outcome it will provides with the outcome available in other alternative destinations.

\subsection{Current state of tourism in Nigeria}

The Tourism sector in Nigeria is unorganized and poorly developed, hence its contribution to the GDP is lower than what it ought to be. Nigeria is one of the most populated countries in Africa with cultural diversity, friendly environment and colourful festivals. Each of the six geo-political zones of Nigeria has something unique to offer to the tourist ranging from forest, beautiful plateau, terrific water fall etc. Unarguably, many Nigerians view tourism as an avenue to practice immorality, resulting to waste of potential in tourism sector. As pointed out by Ekanayake and Long (2012) "unless economic policies to promote tourism remain a focus in developing countries, tourism will not be a potential source of economic growth". However, awareness created by the Nigeria tourism development commission (NTDC)has yielded positive results as many Nigerians perception of tourism has changed.

\subsection{Tourism as a product}

Tourism could be viewed from many perspectives, this is so because among tourism scholars and experts, consensus has not been reached and boundary has not been drawn on where tourism begins and end. Holistically, tourism encompasses transport services, hospitality service, human component etc. and even some of the intangible elements of our environment. As a product, tourism is the aggregate of what a tourist is seeking for in a destination or the motive of preferring a particular destination over the other. This meansthat tourism does not only mean a relaxation in a hotel bed, visit to the beach, but rather an amalgam of many parts fused together or packaged for the tourist to consume at the destination where it is produced or supplied.

\subsection{Marketing of tourism product/service}

Tourism will not yield the desired benefit, if its product and service does not get to the final consumer (tourist). As observed by Cox \& Shapiro (1964), there is always a separation between the producer (destination) and the buyer (Tourist). This "gap" must be filled to ensure that tourism contributes effectively in the area of promoting economic growth, alleviating poverty, creating jobs as well as contributing to the other macroeconomic objectives of the country. It should be noted that the "link" between tourism products and services with the tourist is tourism marketing.

Tourism marketing is the process aimed at satisfying the tourist needs and wants through exchange of goods and services by the individual (host) and the institution (destination) at a profit. Marketing is very essential in tourism sector because no tourist would embark on a vacation to a given destination without prior information on the existence of tourist product and service worth patronizing, this is so because tourists are assumed to be rational. As argued by Anyanwu (2009) each of the 4ps (product, place, price and promotion) remain the component of marketing communication in addition to the other activities of a firm. In tourism marketing, the emphasis is on the interrelated function of the marketing activities geared toward the satisfaction 
of the tourist (consumer) and the destination (producer). Thus for a tourist product to be appreciated in the market by it consumer (tourist), the four concepts in the marketing mix must present, in other words, the price of the tourist goods and services must be of desiredquality, the place (destination) must be fascinating and appealing to the tourist whereas promotional package would increase consumer (tourist) demand and volume of arrival.

\subsection{Advantage of tourism products over other products}

Tourism products have some distinctive features that give them edge over other products. Tourism is a composite product that is consumed at the point of supply, this has a lot of positive effect on other sectors of the economy because of the interrelationship between tourism and other sub sectors. From the perspective of the producers, the image, branding and packaging of various tourists' demand in the manner and methods suitable and acceptable by the tourist is what constitute the product which is "gathered" from many sources and made available to the tourists in refined form. For Nigeria to strive for macro-economic stability, the need for economic diversification is a child of necessity as posited by Abiodun \& Odularo (2006). Tourism provides a necessary training ground for creation and development of entrepreneur in several sub sectors of economic activities.

\subsection{Satisfaction of tourism}

Satisfaction is said to exist when the expectation of the tourist are met. Before embarking on any strip for the purpose of tourism, the tourist must have pre-travel expectation and this pre-travel expectation is usually compared with the actual experiences. If the pre- travel expectation is equal to the actual experience, then tourist satisfaction has been achieved. In tourism/hospitality sector, satisfaction is a very sensitive issue because tourism is a 'puller' of foreign direct investment and dissatisfied tourists will not only stop coming to the destination but will discourage others visiting such destination. As observed in William \& Shaw (2002) "the spring board for the national economy to attract premium from tourism depends on the availability of investment to develop the necessary infrastructure and on its ability to supply the needs of tourists.

\subsection{Economic relevance of tourism in Nigeria}

Agriculture used to be the backbone of Nigeria economy before the discovery of crude oil in the early 1970s. Since the discovery of crude oil, it has become the main stay of Nigeria economy with attendant effects such as rural urban migration in search of employment in oil sector. The over concentration on the oil sector led to a serious inequality and lopsidedness in the economy because other sectors of the economy such as tourism that could generate much needed revenue were neglected. With the frequent fluctuation in the oil price which has caused a decrease in government revenue, the policy makers have now decided to use tourism as a tool for economic transformation because they believe the economic might of tourism sector can help to achieve the desired macro-economic objectives.

This is predicated on the fact that tourism has been an effective tool and revenue source in countries that have proactive tourism industry as noted by Olayinka \& Bello (2010). Nigeria is rich in natural attraction, and developing tourism based on these will offer the sector some comparative advantage over other economic sectors. Besides, tourism improves employment opportunities, not only one-off employment situation, job is in continuous flow during the construction of tourist infrastructure in the destination for all classes of human capital because tourism is labour intensive. It is a known fact that there is a consensus among experts on the importance of tourism to the economy of any country, for instance tourism facilitate the exchange of cultural, recreational and educational value in Nigeria.

\subsection{Impediments to tourism}

There are many setbacks to the growth of tourism in Nigeria today; the most common threat comes from the infrastructural sector of our economy. For instance, poor road network has constituted a major problem to tourism development in Nigeria. Most tourist sites in our country however, are not accessible due to lack of access roads. There would be no marketing of any tourist attraction regardless of how fascinating it appears to be when there is no road to transport tourists down. This therefore present a challenge to the government to embark on road construction to some of the inaccessible tourism sites in the country so as to fulfill the role of providing the enabling environment for a sustainable development of tourism. Besides that, the insurgency of Boko Haram in some Northern States of the country has caused a decrease in the activities of the tourism sector because tourists are scared of violence. However, the Nigerian government has been tackling these societal ills for the past twelve's years. Investors are therefore called upon to come and invest in the abundant tourism potential in the country. 
Empirical analysis of financial contributions of tourism to the gross domestic product of nigeria.

\subsection{Lucrative opportunities in Nigeria tourism sector}

Nigeria is richly blessed with natural attractive sites which are scattered all over the length and breadth of the country, but only few are developed to viable stages, a good number of these attractive sites are begging for attention from both government and private enterprises. For instance, data available from unpublished sources show that there are about eighty-five tourist sites identified in Cross River State, South- South, Nigeria, but only forty sites have been developed .

Besides, tourism is a conglomeration of many industries with link in other sectors of the economy. Since tourism activities cut across all other sectors of the economy, such as transportation, health employment etc., it can be said that the development of these other sectors would create good market for tourists. Tourism stimulates the exchange of value, norms and culture. This is so because when tourists meet with their host destination, there is bound to be an exchange of educational and cultural ideologies.

\subsection{Culture and tourism in Nigeria}

Culture and tourism practice are compatible institutions. They do not only attract visitors to the destination but also contribute significantly to the national economy. Although the two institutions can exist and function independently, a combination of both is more attractive to the people. A well preserved culture can enhance the beauty of tourism. In like manner a well planned and developed tourism sector is the spring board and a showcase on which our cultural values are shown to outsiders.

However, the two institutions seem to be facing a common problem in Nigeria. There is total condemnation by some members of new generation churches who see nothing good in tourism and cultural practice. Such condemnation should be avoided because of the negative effect it will have on our economy. Tourism serves as a natural vehicle through which visitors travel to see foreign culture, while culture itself is the language through which destination communicate their core values to the tourist, hence there is always an exchange of cultural value between the tourist and the host communities.

\subsection{Cultural tourism}

The universal acceptable definition of culture to the understanding of a layman is "the way of life of a people or group of people". Human beings in any part of the world have their culture as far as they exist. Hence cultural tourism is traveling to places and experiencing activities that authentically represent the stories and people both past and present. In other words, cultural tourism is the search for and participation in new and deep cultural experience; be it aesthetic, emotional, psychological or intellectual. The characteristics of culture include, arts work, music, food, dance, dresses, festival, custom, etc., and these characteristics differ from one culture to another, hence the need to experience other peoples culture which attract and fascinate the tourist. Nigeria culture emphasizes hospitality, for instance traditional sport, like wrestling, funeral ceremonies, traditional marriage, traditional religious practice etc. are not only attractive but appealing to the tourists. In Nigeria, festival and tourism are like Siamese twins and are compatible businesses; wherever the later goes, it drags the former and their combination does appeal to most people.

\subsection{Effect of fiscal policy on tourism sector in Nigeria}

Fiscal policies are the use of taxation and alteration of government expenditure to effect change in the level of economic activity to achieve some predetermined objectives. Agreeable fiscal policy is pivot on which a nation's economy revolves, thus the disposable income of households and firms as well as the entire business atmosphere is affected by the tax and expenditure of government. Based on this, the link between the public sector finance and tourism sector contributions is of great concern. Conversely, government expenditure provides the most needed spring board for the growth of tourism sector, on the other side, if deficit budget is in practice for a particular fiscal year; it will be harmful to the growth of tourism because the few available financial resources will be shared among the various sectors of the economy competing for fund. In such situation the crowding out of the sector by the government can do more harm to them than any short term benefit of an expansionary fiscal policy.

It is on this note that Okonjo-Iweala (2003) posited that the panacea to all these is striking a sound balance in fiscal management thereby having enough expenditure outlay to carter for the need of government and also enhance economic growth, but not to the extent of denying the organized private sector the necessary resources needed to invest and develop. It is an established fact that aggregate output is affected by both the effect of revenue and expenditure. Thus the consequence is completely different when government expenditure is grafted with tax policy. Tourism also has a long term effect on fiscal policy in tourism exporting countries because it contributes significantly to the revenue of government. 
Empirical analysis of financial contributions of tourism to the gross domestic product of nigeria.

\subsection{Tourism and religion in Nigeria}

Tourism is closely linked with religion and its growth in most parts of the world and depends largely on the history of religious activities in those countries. Nigeria's history of religion if properly and adequately packaged would attract a great deal of local and international tourism considering the rising curiosity to visit such religious site through pilgrimage and mission. Unfortunately, this is one aspect of tourism in Nigeria that has been left to die notwithstanding the attendant economic benefit arising therefrom.

Early Christian missionary activities in Africa especially along the West African coastal region flourished leaving lasting legacies, in the memory of visiting tourist. It is an established fact that tourist traffic to Jerusalem on yearly basis has remained on the increase as thousands of religious faithfuls from Christian fold across the globe embark on pilgrimage to watch the wonder of the old Isreali confederacy while Muslim pilgrimages to Saudi Arabia is no doubt the largest single gathering in the world which Islamic faithfuls across the globe travel to Mecca to pay homage to the Land of their founding father, prophet Mohammed.

History records that far back in 1482, after the voyage of John Alphonso d' Aveiro, many Portuguese traders were said to have settled in Benin, this influenced the decision of the Oba of Benin to send his son to Portugal for education. These missionary cum traders built churches at Warri and Benin, most of these historical church buildings and their personages are still available today and can be marketed in Portugal and beyond after providing a blend of ancillary tourist facilities and services at the various sites. It is advocated that the attention of religious tourism in Nigeria should focus principally on the three dominant religions practiced in the country, ie, Christianity, Islam, and traditional African religion. The basic emphasis is to harness their archaeological as well as the theological history which constitute one of the factors responsible for the development of black civilization. Religion ab-initio is a form of culture hence, the African traditional religion in particular has contributed immensely in shaping and developing the rich African culture since religion and culture represent the way of life of the people. A comparative advantage derivable from the patronage, especially by foreign tourists depends on confidence and pride of Africa and the level of appreciation they have for their culture.

A notable character who boosted religious tourism in the Calabar area of Nigeria is Mary Mitchell Slessor, a Scottish missionary, born in December 2, 1848, in Aberden, United Kingdom. She is fondly remembered for putting an end to the killing of twin babies in Nigeria. She died and was buried at the Duke Town Cemetery near Calabar in January 13, 1915. This history can equally invoke a feeling of a tourist to visit this part of Nigeria if properly marketed.

\subsection{The significance of tourism development in the Nigerian economy}

The Federal Military Government blue print on tourism was launched in 1990 to demonstrate government commitment to the development and promotion of tourism as a viable industry. The main trust of the National tourism policy is to generate foreign exchange, generate employment, encourage even development, and promote tourism based rural enterprises; accelerate rural urban integration and cultural exchange. As observed by Lanaza and Pigliaru (1999), tourism no doubt is the world's largest single invisible export trade with overwhelming multiplier effect. Considering the above blue print and giant stride of the Federal Government, it clearly reveals the drive towards dismantling the huge structure of mono-economy as evidenced by total self-reliance on crude oil which today account for about $80 \%$ of the gross domestic product, hence the main stay of the national economy. It is an established fact that since the discovery of crude oil in the 1960s in Nigeria, all economics attention got focused on oil to the detriment of all other sectors that had sustained the country's economy. When the popular and widely publicized oil boom started dwindling and the tide turned adversely against the country's economy, the government then saw the need for economic diversification.

\subsection{Economic leakages and cost variation of tourist spending in Nigeria}

While tourists from developing countries may spend a lot of money to visit their developed counterparts, most of the expenditure does not benefit the local population. The World Bank estimate reveals that only $45 \%$ of the revenue raised by tourism reaches the host country, much of the money flood back to the developed nations by way of oversea tour-operation, foreign airline and foreign owned accommodation. In some countries unlike Nigeria, foreign earnings from tourism may be negative as more people are prone to travel abroad and spend their money in foreign holiday resorts rather than patronize their home destinations.

Following the problems of devaluation of currency and continuous depreciation in the fiscal policy of African countries with Nigeria as a case study, foreign tourists purchase services at cheaper rate than domestic tourists in Nigeria, the result of which arise from the disproportionality in the value of naira compared to hard currency. Economic leakages are experienced in Nigeria when tourists from Nigeria develop a habit of spending thrice offshore the amount that would have been enough for a holiday in Nigerian resorts. However, the advantage and disadvantage of tourism spending depend to a large extent on the prevailing monetary value and exchange rate in a particular destination. 
Empirical analysis of financial contributions of tourism to the gross domestic product of nigeria.

\subsection{Balance of payment from tourism}

Worldwide tourism generates an estimated four trillion dollars annually. Tourist travel to different parts of the world spending huge sums of money at various destinations as argued by Francesco Frangialli, secretary general of the world tourism organization. "Tourism and peace are inseparable; the ventral forces unleashed by tourism are so powerful that they can change apparently irreversible situation and bring about (financial) reconciliation where non was considered possible" (WTO 2009). History of tourism in Africa indicate that East African countries such as Kenya, Mozambique, Tanzania, etc. had benefited immensely from tourism by reason of their long term foresight, early feasibility study on its lucrative nature, tourism planning, development and aggressive marketing of the industry. This had no doubt contributed greatly to their National earnings, boosting the gross domestic product, increasing per capita income and solving the problems of balance of payment deficit.

Nigeria can properly fit into this financial boom by virtue of her enormous tourism potential ranging from diverse species of wildlife and aquatic creatures, alluring sandy, beaches, beautiful green vegetation of her mangrove forest, unique cultural dynamics capable of boosting cultural tourism, above all very friendly people. These are all marketable tourism products in Nigeria.

\subsection{Tourism as a tool to enhance foreign exchange in Nigeria}

Tourism is positioned as the forth-sector industry in the world after fuel, chemical and automobile product (UNWTO, 2009); this was proven that it is a potent sector in the world economy. More developing countries including Nigeria are using tourism as a means to enhance their foreign exchange base,as observed by Ayeni (2012). The developing countries now have tourism as key foreign exchange earner. According to world tourism organization (2011), Nigeria accounted for annual average of $17 \%$ of international tourism expenditure in Africa, spending a cumulative total of US\$2, 794 million, next to South Africa. However South Africa accounted for an annual average of $24.1 \%$ of international receipt on tourism in Africa over the same period; Nigeria annual average share was $0.73 \%$ as observed by Zehnna (2002).

\subsection{Method of measuring grossdomestic product}

Traditionally, gross domestic product can be determined by using any of the different approaches, the total products, the total income and the total expenditure techniques, which should give the same result. The product approach considers the aggregate monetary value of output produced by enterprises/institutions in the economic sector within the year, the expenditure techniques work on the principle that every product must be bought by somebody, hence the values of total output must be equal to the total expenditure in buying products and services. The income approach work on the principle that the income of the factors input must equal the value of the product.

\subsection{Indispensability of hotelsin tourism}

The output of hotels is the main determinant of whether tourism increase, decrease or remain static in a particular environment. This is based on the assumption that their product and service is tourist oriented. Hotels serve as a link between the tourists and their destination and provide the tourist with 'home away from home'. Hence there is an obvious need to build hotels in sensitive tourist sites to cater for the accommodation needs of tourist. Hotels and restaurants offer continental and local cusine to the tourist. In the Calabar area of the SouthSouth, Nigeria famous among the local cusines are 'Afang' "Edikanikon" Ekoki' and "Ekpan nkukwo Ikon". The impact created from these variety of products and branded menu remain a consequence of a sustainable growth of tourism in the country.

\subsection{The role of transportation intourism}

Transportation could be by air, land or sea. Land transport include car hire service, horse racing, etc. while sea transport comprises of canoes, boats, ship; air transport is shuttled by airplanes, helicopters, cable car etc. All these mediums of transportation operate in the tourism cycle to ensure that the tourist get in contact with the actual destination. Adventure in the sea is an interesting and delightful area of tourism especially for domestic and international tourists originating from coastal region, for instance the Calabar Marina Beach in Cross River State, Nigeria has such potential of beach tourism where tourist can be engaged in swimming competition, canoe paddling competition and boat regatta.

Transportation is life wire to the development and marketing of tourism in Nigeria, especially air transport which has brought a great revolution in tourism globally. Most tourists have developed a habitual buying behaviour in choices of transportation, perhaps, due to accessibility to time and disposability to income. In any case the disparity in choice of transportation is more a question of habit rather than brand loyalty. As posited by Esu and Eze (2004) "some tourists are actually financially stable" and could afford to pay the air 
transport fares while on vocation but would prefer to make a substitute means of transporting themselves to the destination due to phobia in air travel.

\subsection{Factors that affect the growth rate of gross domestic product}

A nation's gross domestic product (GDP) represents the economic market value of the goods and services that are produced in that country. A growth in gross domestic product is said to occur when there is an increase in the total value of goods and services produced in the current year when compared to the previous years, and also increase in per capita, all things being equal. There are specific factors that affect gross domestic product growth; some of which are (a) available economic resources at cheap prices, (b) high labour turnover and (c) increase in output demand etc. All these factors occur differently in each nation and ather times different factors can play a role.

Therefore, growth in gross domestic product is not something every nation experiences at the same times or through the same factors. Gross domestic product as asserted by Iyoha, Oyefusi and Oriakhi (2003) is the market value of all officially recognized goods and services produced within a country in a year. Gross domestic product percapita is often considered an indicator of a country's standard of living.In other words, it is thetotal volume of production that has taken place in the economy,irrespective of the nationality of the people who produced the goods and services (Buhari 2011).

There are three ways of determining gross domestic product; all of this should in principle give the same result. They are:

(a) Production (output) approach: Under the approach, two methods may be used in arriving at the value of the national income, (i) either by estimating the value of all final goods and services produced during the course of the period or (ii) by estimating the national income through the output approach, that is the value added approach .

(b) Income approach: Here the income earned by all the factors of production during the course of the year is added up.

(c) The expenditure approach:The expenditure approach measures the total value of expenditure on goods and services by individuals, private business firms and government during the year.

\subsection{Negative impact of tourism}

Although tourism has been seen as a sector to bring about the needed turnaround in the economy of any country, the expected benefits will not materialize unless adequate economic policies are put in place to promote tourism as stated by Ekanyake and Long (2012) and suitable Legal framework to checkmate the negative impact of tourism. Tourism like any sector of the economy has some negative effect on our socio-political setting. For instance, the cross fertilization of socio-cultural ideology between the tourist and the host communities may result to undiserable borrowed culture. Also psycho-social abnormality such as prostitution, drug trafficking, disruption and overcrowding of traditional activities, invasion of privacy are some of the offsprings of tourism.

\subsection{Empirical review of study by Elizabeth and Mark on tourism contribution to the economic development in Kenya (2009)}

According to a research carried out by Elizabeth and Mark of the Department of Applied Economics, University of Balearic Island, Palma, de Mallorca, Balearic Spain in 2009, it was discovered that as in many other developing countries, tourism is one of the key drivers of Kenya socio-economic developments. Kenya depended mainly on its export of agricultural products just like Nigeria depends on oil for foreign exchange. However, with the decline in world market prices of petroleum products Nigeria has turned to tourism as an alternative. For Kenya, it has been argued that tourism represents a cheaper alternative for diversification of the economy particularly considering the country's competitive advantages in terms of environmental attraction suitable for native tourism.

According to the study, the Kenyan government 2003-2007 economic recoverystrategy for wealth and employment generation, places emphasis on tourism, identifying it as the main driver of the economy in the planned period because tourism accounted for an average of $60 \%$ of modern, private and public sector direct employment in Kenya. It should be pointed out here that this figure does not represent the total share of tourism in employment, as indirect employment, particularly in the informal sector, may have a higher percentage.

\subsubsection{Empirical review of study by Esu and Eze on tourism contribution to the economic development of} Nigeria (2004)

Esu and Eze (2004) of the Department of Marketing, Faculty of Management Sciences, University of Calabar, also pointed out that tourism is receiving global attention today because of its economic, social, cultural and political relevance and that Nigeria has been grappling with tourism policies implementation in the past twenty years. They further stated that Nigeria like any other developing country of the world is confronted with 
three major problems; first, is the need to reduce the level of poverty, second is the need to tackle the serious problems of environmental degradation and third is the need to find solution to the ever-growing number of crisis emanating fromenergy and resources locally and internationally.

However, since the inception of President Obasanjo's led government; the trend has shown that there is a promising future for the industry (Fagbile 2001, Ukene, 2003: as in Esu \& Eze, 2004). A few examples of these are the preparation of tourism master plan for Nigeria, the recent constitution of a ministerial committee for tourism development, the establishment of state ministries of tourism and the enactment of tourism bill in Nigeria.Nigeria appears to have a competitive advantage in tourism development because of her rich natural resources and cultural heritage. The problem that seeks our answer is whether the development of Nigerian tourism potentialadds to the nation's wealth or not. And if it does, make recommendations that would help government and destination managers achieve the goal of making tourism one of the highest revenue earners of the country.

\subsection{The role of telecommunication in tourism development in Nigeria}

In this modern age of information communication technology (ICT), business is supposed to be transacted at the speed of light. The information revolution is being accentuated by social media. Curiously, every sector of the economy is key into this revolution including tourism.

Basically, tourism strives on useful information, thus the revolution in telecommunication as witnessed in Nigeria pinpoint the obvious fact of an attempt to "influence" member of the target market, (tourist) whose demand for tourism could only be realized through modern telecommunication.Before now, tourist found it difficult to relate or make contact with people away from destination, but the reverse is now the case as tourists can afford to reach out to their loved ones even from suburb of the most remote part of the country. The corresponding impact in the circumstance is the rise in the overall tourists' receipts in the country. The emergence of global system for mobile telecommunication provides and makes communication and information dissemination less stressful especially in the tourism sector. Both domestic and international tourists havechoices of each network to possibly ask of pre- information about existing product and cost offered for them.Telecommunication is one of the supply component of tourism, this supply component include all that a destination can offer to its actual and potential visitors, and it represents the combination of natural and manmade attraction, services and goods that are likely to induce tourist to visit a destination as stated by Mbaiwa (2009).

Tourists are full of adventure and highly curious, therefore a basic characteristic of a tourist is that of moving from place to place in search of new attraction, hence require the service of mobile gadget of communication which obviously play a prominent role in maintaining a steady communication flow. Useful information about the existence and the state of destination as well as the product offered could nonetheless be assessed through other communication mechanism for instance computerized information technology.

\subsection{Need for private and voluntary agency participation in tourism.}

Tourism is about providing assets for people to invest in, but they will not invest in assets unless there is a revenue stream from that investment and a return on their capital. What then are assets that we have in Nigeria in relation to tourism? Nigeria is blessed with waterfall, caves, hotels, parks, sandy beaches, large lake and historic sites. Nigeria is able to offer a range of tourism experience applicable to the general holiday maker as well as the traveler looking for something off the beaten track. As posited by Ayeni (2012) "the growth of national economy to a large extent depend on private sector participation alongside some voluntary agency involvement since government has no intention to embark on full time business as done by the private sector". The role of government is to consider the requirement for congenital relationship as well as provide the enabling environment capable of attracting local and foreign private investment. Government equally provides technical assistance to the tourism sector while private enterprise strives in the main tourism business.

A case study of Pakistanian government with respect to creating an atmosphere capable of inducing private sector participation implies that all tourism related facilities including fun lands, amusement parks, hotels, motels, cultural centers, travel agencies, tour operators, transportation bus sector, tourist service agencies, handicraft and souvenir manufacturing etc. be treated with industrial concern (Ukpana, 2012). Further analysis on the subject matter suggest that all fiscal and monetary incentives provided by government to the export oriented industries be admissible to the tourism related projects alongside regular tourism policy implementation forum being an institutionalized machinery for regular consultation between public and private tourism players as well as creating opinion pool for stakeholders to facilitate the planning, development and marketing of tourism.

While government provides an enabling environment through legislation and investment friendly policies for the overall progressive development of tourism, it is the private sector that provides the supply segment of the tourism industry. Such supplies include accommodation, transportation, and entertainment and 
shopping facilities etc. Though, the private sectors operate in Nigeria on a comparatively free market by separate corporate entities and sole proprietorship, it has been found necessary that for obvious business reason, there should be some area of collective cartel. Tourism the world over is private sector driven with initial investment cost arising from private limited liability companies, partnership or sole proprietorship. The private and voluntary tourism sector initiative remain a catalyst to a consistent growth of the industry particularly where government policy with tax rebate, return of investment and provision of local schemes with minimal interest rate are guaranteed as a means of boosting the private investor in the industry.In Nigeria, for instance, some tourism experts have advocated the existence of collective cartel instead of the comparative free market operation by several corporate entities involved in tourism business.

\subsection{Conservation of our environment through eco-tourism}

Nwoboshi (1990) asserted that as human pressure on tropical forest grows conservation need new approaches; this new approach is ecotourism. In fact the basic necessity for conserving nature is for tourism and educational research to focuse on preserving specific biological interest depending on government policy. Since 1930s, many developing countries have established national parks and natural reserves; usually, the aim is to protect the ecosystem, but since ecotourism became a global focus as a means of generating revenue from nature without destroying its reserve, the scope of developing ecology for tourism purpose has truly broadened. However, several factors had contributed to the prevailing threat on the ecosystem. This ranges from poverty and corruption, the result of which is poaching of various species of wildlife especially the endangered ones in the various game reserves.

\section{Research design}

The ex-post facto design is suitable for this study where the financial contributions of tourism to gross domestic productfrom 2000 - 2015 are being investigated. It is economical for measurement of several of these variablesmore so, the researchers have no direct control over the independent variables since they have already occurred in the population.

\subsection{Model specification}

The model for the study was econometrically specified as:

$\mathrm{GDP}_{\mathrm{g}} \quad \mathrm{F}(\mathrm{b} 1 \mathrm{gTC} \pm \mathrm{b} 2 \mathrm{gEMP} \pm \mathrm{b} 3 \mathrm{gOS})$

Where:

$\mathrm{GDP}_{\mathrm{g}} \quad=\quad$ The growth rate of gross domestic product

gTC $\quad$ Growth in tourism contribution

gEMP $\quad$ Growth in employment level

gOS $\quad=\quad$ Other related sectors

\subsubsection{Measurement of growth}

Based on the above model, growth rate is measured by comparing the actual year contribution of tourism to the gross domestic product with the previous year contribution. The difference when it is positive means an increase and vice versa.

\subsubsection{Basic assumption of the model}

The following are the basic assumption of the above model:

a. The growth rate of tourism is ever increasing. This is assumed to be so because a decrease in tourism contribution will automatically decrease the gross domestic product of a given economy, all other things being equal. In other words, the growth rate is assumed to be one (1) or greater than one (1).

b. The growth rate in tourism output trigger the rate of employment: this assumption is premised on the fact that as tourism sector is growing the multiplier effect will be felt by the labour market.

c. Interrelation between tourism and other sector: Here tourism is assumed to be connected either directly or indirectly to other sectors of the economy, that the activities of other sectors can make or mar tourism contribution to the GDP. For instance, the infrastructural sector of the economy, provision of basic amenities, electricity etc.

\section{Data presentation}

This section is concerned with data presentation, analysis, and interpretation of results and findingsof the study. 
Empirical analysis of financial contributions of tourism to the gross domestic product of nigeria.

GDP at Current Basic Price

Table 4.1

\begin{tabular}{|l|l|l|l|}
\hline S/N & YEARS & GDP & GRGDP \\
\hline 1. & 2000 & $2,80,1972.60$ & 3.672355329 \\
\hline 2. & 2001 & $2.708,430.90$ & 3.33842382 \\
\hline 3. & 2002 & $2,708,430.90$ & 17.92861364 \\
\hline 4. & 2003 & $4,582,127.30$ & 43.4597938 \\
\hline 5. & 2004 & $4,725,086.00$ & 3.119920093 \\
\hline 6. & 2005 & $6,912,381.30$ & 46.29112042 \\
\hline 7. & 2006 & $8,487,031.60$ & 22.78014281 \\
\hline 8. & 2007 & $11,411,066.90$ & 34.4529806 \\
\hline 9. & 2008 & $14,572,239.10$ & 27.70268753 \\
\hline 10. & 2009 & $18,564,594.70$ & 27.39699491 \\
\hline 11. & 2010 & $20,657,317.70$ & 11.27265619 \\
\hline 12 & 2011 & $24,296,329.30$ & 17.61608975 \\
\hline 13. & 2012 & $24,794,754.70$ & 2.049319319 \\
\hline 14. & 2013 & $33,984,754.10$ & 337.06714128 \\
\hline 15. & 2014 & $37,543,654.70$ & 10.47205037 \\
\hline 16. & 2015 & $44,856,965.20$ & 19.47948479 \\
\hline
\end{tabular}

Source: IMF World Development outlook 2015, CBN Statistical Bulletin 2015

Table 4.2

GDP at factor cost

\begin{tabular}{|l|l|l|l|}
\hline S/N & YEAR & TC & GTC \\
\hline 1. & 2000 & 4285.70 & 28.75112282 \\
\hline 2. & 2001 & 4865.11 & 13.51961173 \\
\hline 3. & 2002 & 5790.65 & 19.02403029 \\
\hline 4. & 2003 & 6455.26 & 11.4772953 \\
\hline 5. & 2004 & 8018.66 & 24.21900899 \\
\hline 6. & 2005 & 9670.03 & 20.5948929 \\
\hline 7. & 2006 & 11421.48 & 18.1121465 \\
\hline 8. & 2007 & $35,249.77$ & 208.6269905 \\
\hline 9. & 2008 & 46080.04 & 30.72437068 \\
\hline 10. & 2009 & 57611.87 & 25.02565102 \\
\hline 11. & 2010 & 72839.43 & 26.43128925 \\
\hline 12. & 2011 & 86058.68 & 18.1484806 \\
\hline 13. & 2012 & 98961.71 & 14.99329839 \\
\hline 14. & 2013 & 113791.81 & 14.98569386 \\
\hline 15. & 2014 & 130821.02 & 14.94519319 \\
\hline 16. & 2015 & 151813.86 & 16.06722127 \\
\hline
\end{tabular}

Source: IMF World Development outlook 2015, CBN Statistical Bulletin2015

Table 4.3

Employment Data from

\begin{tabular}{|l|l|l|}
\hline Year & No. employment $(\mathrm{m})$ & Difference \\
\hline 2000 & 52.1 & - \\
\hline 2001 & 52 & -0.1 \\
\hline 2002 & 57.9 & -0.1 \\
\hline 2003 & 51.9 & 0 \\
\hline 2004 & 51.8 & -0.1 \\
\hline 2005 & 51.8 & 0 \\
\hline 2006 & 51.8 & 0 \\
\hline 2007 & 51.8 & 0 \\
\hline 2008 & 51.8 & 0 \\
\hline 2009 & 51.8 & 0 \\
\hline 2010 & 51.8 & 0 \\
\hline 2011 & 51.8 & 0 \\
\hline 2012 & 51.8 & 0 \\
\hline 2013 & 51.8 & 0 \\
\hline 2014 & 51.8 & 0 \\
\hline 2015 & 51.8 & 0 \\
\hline
\end{tabular}

Source: IMF World Development outlook 2015, CBN Statistical Bulletin 2015. 
Empirical analysis of financial contributions of tourism to the gross domestic product of nigeria.

Table 4.4

Regression result between GDP and independent variables (Tc, Emp and Ors)

\begin{tabular}{|l|l|l|l|l|}
\hline Variable & Coefficient & Std Error & T. Statistics & Prob \\
\hline C & 512.1094 & 323.0235 & 1.585363 & 0.1389 \\
\hline LOG (TC) & 0.970570 & 0.310279 & $2.805764^{*}$ & 0.0159 \\
\hline LOG (Emp) & -126.1074 & 80.39167 & -1.568662 & 0.1427 \\
\hline LOG (OS) & -0.544812 & 0.723593 & 0.752926 & 0.4660 \\
\hline
\end{tabular}

$\mathrm{R} \quad=\quad 0.981676$

$\mathrm{R} 2 \quad=\quad 0.977095$

Dw $\quad=\quad 1.57$

F. Statistics $\quad=\quad 214.2926$

Prob.(F - Statistics) 0.000

*Significant at 0.05 level

Source: Researchers' computation

\subsection{Data analysis}

Data obtained were subjected to appropriate statistical analysis, and then interpreted and discussed accordingly. The hypotheses that were formulated for the study were tested at a 0.5 level of significance.

The growth rate of gross domestic product (GDP) is the dependent variable while the independent variables involved were:

a. Growth in tourism financial contribution (TC)

b. Growth in employment contribution (GMP)

c. Growth in other related sector (ORS)

Table 4.1 shows the actual yearly value for the dependent variable (GDP), its growth rate in percentage from 2000 - 2015. The growth rate of the gross domestic product from 2000 - 2015 keep fluctuating depending on the macro-economic activities in a given fiscal year.

Table 4.2 shows the yearly contribution of tourism to the GDP and its growth rate $2000-2015$. The variation in the growth rate depends on the political orientation and the philosophies of those in power in a particular year. For instance, from 2004 the growth rate of tourism contribution increased to 20\% in 2007, 30\% in $2008,25 \%$ in $2009,36 \%$ in 2010 , and dropped to $18 \%$ in $2011,14 \%$ in 2012 and $14 \%$ in 2013 . The increase in the contribution was due to the fact that Nigerian government instituted a new set of reforms in the tourism industry with the aid of United Nation while the drop in the tourism growth to the gross domestic product may be as a result of effect of Boko-Haram activities and other counterproductive activities engaged by men of the underworld.

Table 4.4 as shown below revealed that $\mathrm{F}(\mathrm{P})$ of 00.000 which means the model is sound to be used to explain the relationship between gross domestic product and the independent variable tourism contributions, employment growth and other related sector contributions. The $\mathrm{R}$ value of 0.981676 revealed positive relationship between gross domestic product and the independent variable (tourism contribution employment level, other relevant sector contribution). Also the $\mathrm{R}_{2}$ value of 0.977095 which is the coefficient of multiple determinant shows that $97 \%$ variation in gross domestic product is caused by changes in tourism contribution, employment and other related sectors contribution. The $\mathrm{T}$ statistics value of 2.805764 shows that there exist a correlation between gross domestic product and tourism contribution

\subsubsection{Test of hypotheses}

Table 4.5

Regression result between GDP and tourism contributions (independent variable). Test of hypothesis one

\begin{tabular}{|c|c|c|c|c|c|}
\hline & Variable & Coefficient & Std Error & T. Statistics & Prob \\
\hline & $\mathrm{C}$ & 8.937831 & 0.326132 & $28.40553^{*}$ & 0.000 \\
\hline & LOG (TC) & 0.714859 & 0.031687 & 22.55994* & 0.000 \\
\hline$=$ & 0.937831 & & & & \\
\hline $\mathrm{R} 2$ & 0.971317 & & & & \\
\hline $\mathrm{F}(\mathrm{P})=$ & 00.000 & & & & \\
\hline F. Statistics & $=$ & 8.0509 & & & \\
\hline Dw & $=$ & 79290 & & & \\
\hline
\end{tabular}

*Significant at 0.05 level

Source: Researchers' computation

$\mathbf{H}_{0}$ : Tourism does not contribute significantly to the gross domestic product of Nigeria.

$\mathbf{H}_{1}$ : Tourism contributes significantly to the gross domestic product of Nigeria. 
The null and alternative form of this hypothesis as stated above indicates that the dependent variables were GDP while the independent variable was tourism contribution.

The T. Statistics value of 22.55999 revealed that there is a significant relationship between GDP and tourism contribution in Nigeria from 2000 - 2015. The null hypothesis was rejected while the alternative hypothesis was accepted.

\section{Table 4.6}

Regression result between GDP and independent variable (tourism contribution and other related sectors contribution). Test of hypothesis two

\begin{tabular}{|c|c|c|c|c|c|c|}
\hline & & Variable & Coefficient & Std Error & T. Statistics & Prob \\
\hline & & $\mathrm{C}$ & 5.404597 & 2.148506 & $2.515514 *$ & 0.0258 \\
\hline & & LOG (TC) & 0.443549 & 0.163032 & $2.751293^{*}$ & 0.0165 \\
\hline & & LOG (OS) & 0.498771 & 0.300175 & 1.661600 & 0.1205 \\
\hline $\mathrm{R}$ & $=$ & 0.977918 & & & & \\
\hline $\mathrm{R} 2$ & $=$ & 0.974521 & & & & \\
\hline Dw & $=$ & 1.461892 & & & & \\
\hline Prob & - Sta & cs) 0.000 & & & & \\
\hline F. St & tics & $=$ & 37 & & & \\
\hline
\end{tabular}

*Significant at 0.05 level

Source: Researchers' computation

2. $\quad \mathbf{H}_{0}$ : There is no significant relationship between tourism related sectors and gross domestic product in Nigeria from 2000 - 2015.

$\mathbf{H}_{1}$ : There is significant relationship between tourism related sectors contribution and gross domestic product in Nigeria from $2000-2015$

From the table 4.5 results, the T. Statistics value is 1.661600 , which means that the relationship of tourism related sector to gross domestic product is insignificant.

Decision: The null hypothesis was accepted while the alternative was rejected.

Table 4.7

Regression result between growth in gross domestic product and independent variable (growth rate in tourism contribution). Test of hypothesis three.

\begin{tabular}{|l|l|l|l|l|}
\hline Variable & Coefficient & Std Error & T. Statistics & Prob. \\
\hline C & 17.68317 & 4.628926 & 3.820145 & 0.0019 \\
\hline GRTC & 0.076125 & 0.082891 & 0.918374 & 0.3740 \\
\hline
\end{tabular}

$\begin{array}{lll}\mathrm{R} & = & 0.056821 \\ \mathrm{R} 2 & = & 0.010549 \\ \mathrm{~F} & = & 0.843411 \\ \mathrm{DW} & = & 1.57\end{array}$

Prob. (F - Statistics) 0.373975

*Significant at 0.05 level

Source: Researchers' computation.

3. $\quad \mathbf{H}_{0}$ : There is no significant relationship between the growth of tourism and gross domestic product.

$\mathbf{H}_{1}$ : There is significant relationship between growth of tourism and growth of gross domestic product.

The null and alternate form of the hypotheses are as stated above indicating the growth ingross domestic product as dependent variable while growth in tourism an independent variable. The t-Statistic value of 0.918374 shows that there is no significant relationship between growth in gross domestic product and growth in tourism contribution.

Decision: the null hypothesis was accepted while the alternative was rejected.

\subsection{Discussion of findings}

\subsubsection{GDP and tourism in Nigeria}

This study revealed that there is a significant relationship existing between gross domestic product of the country and tourism contribution. This finding is in agreement with Esu and Eze (2004) who found in their research that there is a correlation between gross domestic product and tourism. And also pointed out that there exist a strong relationship between tourism financial contribution and gross domestic products in Nigeria from 1993-2002. 
Empirical analysis of financial contributions of tourism to the gross domestic product of nigeria.

\subsubsection{Other tourism related sector and GDP}

The study revealed that there is no significant relationship between other related sectors that are linked to tourism and gross domestic product.This finding disagrees with the finding arrived at by Addo (1997) in Ghana which stated that other sectors contribution and tourism contribution influence gross domestic product immensely. The reason for our finding being at variance with that of Addo (1997) could stem from the fact that here in Nigeria there is inadequate health facilities to cater for the health needs of the tourist and also poor road network which consequently reduced the contribution of this sub sector to the gross domestic product.

\subsubsection{Growth in GDP and growth in tourism}

The study revealed that there is no significant relationship between growth in tourism and growth in gross domestic product.The finding disagrees with the finding arrived at by World Tourism Organization (2009) which asserted that growth in tourism will automatically lead to the growth in gross domestic product. This could be due to the fact that gross domestic product may be declined because of decrease in other sub sectors contribution even when there is a growth in tourism.

\section{Summary of the study}

The study was concerned with assessment of the financial contributions of tourism to the gross domestic product in Nigeria from 2000 - 2015.The study was aimed at determining financial relationship that exists between these major variables: gross domestic product, tourism contribution, and tourism related sectors of the economy. Three hypotheses were constructed in order to give the study a focus. Secondary data were obtained from CBN and NBS. The data obtained were quantified and analyzed using ordinary least square multiple regression techniques.Each hypothesis was then tested for significance at 0.05 alpha level of significance.

From the results, the following were found:

1. Tourism contribute significantly to the gross domestic product of Nigeria from $2000-2015$.

2. There is no-significant relationship between tourism related sectors contribution and gross domestic product in Nigeria from 2000 - 2015.

3. There is no significant relationship between growth of tourism and growth of gross domestic product in Nigeria from 2000 - 2015.

\subsection{Conclusion and Recommendations}

Based on the finding of the study, it is concluded that Nigeria should stimulate tourism sector so as to enable it contribute maximally to the gross domestic product. This is based on the fact that there exist a significant relationship between tourism contributions and gross domestic product. The implication of these finding is that Nigeria should stimulate her economy in order to enhance her gross domestic product, and tourism serves as a means to this. Based on the findings and conclusion of the study, the following recommendations were made: To address the issues of inadequate gross domestic product, government must pursue policies that would positively impact on tourism and per capita income. Some of these should include addressing the problem of social and economic infrastructure like power, communication, transport, health etc. Since there isno-significant relationship between tourism related sector contribution and gross domestic product, government should address, tackle the problem of the sector to enable it contribute significantly to the gross domestic product of Nigeria.

It is recommended that government should pursue its reform agenda very strongly. This would address issues in transportation sector, health sector and other sectors that can impact on tourism. Besides, the following are also recommended; researchers who are interested in the subject of determining the

financial contribution of tourism to the gross domestic product should go beyond the scope of this study; and similar study could be carried out, but by investigating other variables that could have some influence on tourism; this is in order to enhance generalization of result.

\section{References}

[1]. Abiodun S. \& Odularo (2006). Achieving the MDGS in Nigeria: issues and option for tourism industry. Revista de Turismoy patrimony cultural Journal, 429-436.

[2]. Addo, N. O. (1995). The impact of tourism on social life in Ghana: Institute of statistical, social and economic research, University of Ghana.

[3]. Ajao, A. (2012). Tourism Get a Thumb up: Thursday live 200 May 2012.

[4]. Anyanwu A (2009). Dimension marketing Ayan Global Publication. April, 2003.

[5]. Ayeni, Dorcas, (2012). Exploring Sustainable tourism. Nigeria for development growth: Online material.

[6]. Buhari, A. L. (2011). Straight to the public finances for student. Ibadan: JIS - Printing.

[7]. Central Bank of Nigeria (2000). Statistical Bulletin Abuja Central Bank of Nigeria.

[8]. Cox R. A. and Shapiro J. (1964). Theory in marketing Chicago: Inwin.

[9]. Ekanayake E. M. \& Lonng A. E. (2012). tourism development and economic growth in developing countries. International Journal of business and finance research, 6(1), 61-63. 
[10]. Elizabeth, V. \& Mark N. (2009). Economic Contribution of tourism in Kenya. Online material. www.conizantcommunication.com

[11]. Esu, B. \& Eze F. (2004). The contribution of tourism to the economic development of Nigeria. (South-South Socio-economic Review 1(1), 145-152).

[12]. Fagbile, A. (2001). Repositioning Nigeria Economic Through Tourism, Strategies andOptions,. Nigeria Tourism, 1(1), 9.

[13]. Feifer M. (2008). Tourism in History. New York: Stein and day publishers.

[14]. Goyang (1998). Organization of tourism. The Nigeria experience, Jos: Matchers publishing ltd.

[15]. Homan, G. C. (1974). Social behaviour. Its elemental forms ( $2^{\text {nd }}$ Ed). New York. Harcourt Brace Jovanovich.

[16]. Iyoha, M. A., Oyefusi, S. A., Oriakhi, D. E. (2008). An Introductory to Modern Macroeconomics; Minded Publishing, Benin City Nigeria.

[17]. Lanza, A. \& Piliaru, F. (1999). Why are Tourism Countries small and fast growing? Retrieved from http://www.veprint.unical.it/:56/1/99-6 pdf accessed on 11/09/2013.

[18]. Long, P. H. (2012). Tourist Impact and Support for Tourism Development in Ha Long Bay, Vietmam: An Examination of Resident Perception: Asian Social Science (8), 28-29.

[19]. Nwoboshi C. (1990) Forest management strategies in Nigeria: Keynote address at National Forestry workshop, Ibadan.

[20]. Mbaiwa, J. E. (2003). The socio-economic and environmental impact of tourism development on the Okavango Delta, North Western Botswana. Arid Environments. 54, 447.

[21]. Mile, E. (1871). History of Consumer demand theory: A Neo-Kantian Rational Reconstruction. (Online material).

[22]. Musgrave, R. A. (1954). Theory of Public Expenditure Review of Economic and Statistic - online material.

[23]. Ndiyo, N. A. (2005). Fundamentals of Research in Behavioural Sciences and Humanities. Calabar. Wusen Publishers.

[24]. Okey, Ovat O. (2003). Tourism and Economic Development in Nigeria: An Empirical Investigation. Global Journal of Social Service. 2(1),33-34.

[25]. Okonjo-iweala N. (2003). Issues in fiscal management: implication for monetary policy in Nigeria. Third annual monetary policy conference proceeding on issues in fiscal management (P3)

[26]. Olayinka K. \& Bello A. (2010) what are the factors determining tourist destination in Africa, Pakistan Journal of Social Science.

[27]. Uduma Oligu N., \& Onukwubu, H. N. (2012). Exporting the Coastal Tourism Potential of Lagos. Sustainable Development. 5(7), $156-165$.

[28]. Ukene, D. (2003). Marketing of Eco-Tourism, A Paper Presented at the $2^{\text {nd }}$ Cross River State Tourism Summit, Held at the State Library Complex, October $\left(23^{\text {rd }}-25^{\text {th }}\right)$.

[29]. Ukpanah J. (2012) Promoting and developing tourism in Nigeria, Abuja: published by the Federal Ministry of trade and tourism.

[30]. UNWTO (2007). International Recommendation on Tourism Statistic (IRTS). Provisional Draft Revisions September, 2001 Madrid.

[31]. UNWTO-2009 Un world tourism organization (UNWTO 2009) world tourism barometer Madrid.

[32]. Webster, S. (1961). Third New International Dictionary Bell and Son London, 24(17).

[33]. William A. \& Shaw G. (1988). Tourism and economic development. London: Belhaven Press

[34]. World Tourism Organization (1996). Tourism: 2010 vision.

[35]. World Tourism Organization (WTO, 2009). National and Regional Tourism Planning Methodologies and Case Studies. London: Routledge.

[36]. Zhehna, L. (2002). Sustainable Tourism Development: A Critique Sustainable Tourism, 11, 459-475. 